\title{
Consideration of the Design Attribute in the 2008 CEAB Accreditation Procedures
}

\author{
David S. Strong, P.Eng. \\ Professor, NSERC Chair in Design \\ Engineering, Faculty of Engineering \\ and Applied Science \\ Queen's University \\ strongd@queensu.ca
}

\author{
Sue Fostaty Young \\ Doctoral Candidate, Faculty of Education \\ Queen's University \\ fostatys@queensu.ca
}

\begin{abstract}
The 2008 Canadian Engineering Accreditation Board (CEAB) "Accreditation Criteria and Procedures" document introduces a significant change in the engineering accreditation process for Canadian engineering programs. Under this new system, each program must demonstrate that students meet specific outcomes for each of twelve attribute criteria specified in the document. In July 2009, the collective NSERC Chairs in Design Engineering were asked by the National (Canadian) Dean's Education Committee to review and comment on the new CEAB accreditation process, particularly with respect to the design attribute. After some preparatory work, a small group of chair-holders and an expert in teaching and learning outcomes assessment met for two days in September to respond to this task. A "design process" approach was determined to be the best way to describe the design attribute by developing a series of high level and lower level outcome statements for each step in the generic engineering design process. It was also clearly determined that design competency could not be described as an attribute separate from the other eleven attributes listed in the CEAB document. In fact, all of the other eleven attributes were inextricably wound into engineering design. This paper will describe the systematic outcomes-based process applied to approach this issue, as well as provide an overview of the results.
\end{abstract}

\section{Preamble}

It should be clarified that much of the content described within this paper is not the sole work of the authors, but was rather a collective effort of them and a number of individuals who also hold NSERC Chairs in Design Engineering. The main group who contributed a weekend of personal time, and in some cases, additional follow-up effort, to work on this task as requested by the Canadian Dean's Education Committee were, in alphabetical order: Ron Britton (University of Manitoba); Peter Gregson (Dalhousie University); Remon Pop-Iliev (University of Ontario Institute of Technology); Warren Stiver (University of Guelph); Peter Wild (University of Victoria); and the authors. Modest additional contributions were provided by Jean Brousseau (University of Quebec at Rimouski), Steve Lambert (University of Waterloo), and Antony Hodgson and Philippe Kruchten (both from the University of British Columbia). The authors also wish to recognize Anne-Marie Pap for her invaluable administrative contributions.

\section{Introduction}

Amongst the myriad definitions for the term "engineering", "creating a product, process, system, or solution to fulfill a need" would be a simplified distillation of the many that describe this profession. Perhaps one of the most eloquent definitions was penned by Brzustowski [1] as "the professional activity of creating artefacts and systems to meet people's material needs, with design as the central creative process, scientific knowledge and economic considerations as its essential inputs, and public safety as its overriding responsibility". It is with this definition in mind that NSERC Design Chairs ad hoc committee set out to consider "design" as one of the twelve attributes cited in the 2008 Canadian Engineering Accreditation Board Accreditation Criteria and Procedures (ACP) [2].

The original and requested intention of this effort was to consider and respond to the specific attribute of "design" in the ACP with respect to quantifiable outcomes. Several Canadian Faculties of Engineering and Applied Science had already volunteered to create a draft "outcomes assessment" example of the overall list of graduate attributes in the ACP. However, given 
the broad interpretation of "design" in engineering, it was deemed worthy of a stand-alone study by the National Dean's Education Committee.

The description of the Design graduate attribute reads as follows from $\mathrm{CEAB}$ ACP section 3.1.4:

"Design: An ability to design solutions for complex, open-ended engineering problems and to design systems, components or processes that meet specified needs with appropriate attention to health and safety risks, applicable standards, economic , environmental, cultural and societal considerations"

It is interesting to note that the graduate attribute description itself is circular; the definition uses the word "design" within its definition.

A further definition is provided in section 3.3.4.3 of the document: "Engineering design integrates mathematics, natural sciences, engineering sciences, and complimentary studies in order to develop elements, systems, and processes to meet specific needs. It is a creative, iterative, and open-ended process, subject to constraints which may be governed by standards or legislation to varying degrees depending upon the discipline. These constraints may also relate to economic, health, safety, environmental, societal or other interdisciplinary factors."

In the NSERC Design Chair's ad hoc committee's initial consideration of the process, it was determined that the best approach to developing a list of appropriate expected outcomes was to build that list around accepted engineering design process. It was expected that once a generic design process was agreed upon, the engineering graduate outcomes would follow, and they did. However, it quickly became evident that the committee could not capture the requirements for design without integrating every one of the other eleven attributes listed in the ACP. It can be argued that this should not have been a surprise. If one accepts Brzustowski's definition of engineering, which contends that design is the "central creative process", then it follows naturally that all other graduate attributes will be found to be nested within the design attribute.

By adopting this design process model to articulate graduate level learning outcomes the committee was able to then cross-reference each of the design element outcomes with the other eleven graduate attributes outlined by the $\mathrm{CEAB}$, demonstrating that the full range of engineering skills and professional knowledge are inherent in the design process.

\section{Learning Outcomes within a Design Framework}

It is through design that engineers enable the innovations essential to societal progress. To this end, educational institutions must ensure that engineering graduates demonstrate an ability to execute design process to achieve solutions that are sustainable, environmentally responsible and ethically and scientifically sound. From applications of fundamental and complex mathematical and scientific principles, through project management and successful communication in multi-disciplinary teams, the design process is the enactment of the gamut of professional engineering skills. There appear to be no engineering skills nor foundational knowledge that fall outside the operations of the design process.

Upon choosing the design process as the framework for assessing the design attribute, the committee set out to describe the expectations they held, in terms of skills and knowledge, for successful graduates of engineering programs. In adopting this backward design approach, proffered by Wiggins and McTighe [3], the committee began with the end in mind - identifying what successful graduates will know and be able to do upon completion of an engineering program in Canada. Once the members of the group reached agreement about the outcome expectations for each phase of the design process the language of the statement was carefully scrutinized. Using the ICE $[4,5]$ model of learning and assessment statements were rewritten in such a way as to represent "high order", program-level learning outcomes.

The learning outcomes that are presented have been articulated within a design process framework that integrates all core competencies and desired graduate attributes. The intention here is to highlight the iteration and integration of both the design and learning processes. While the framework is presented in a linear format, the overall process is, in fact, highly iterative. Design relies on a combination of creativebased divergence processes and analysis-based convergence processes with any number of other elements running concurrently.

In successfully completing a 4-year program, graduates from Canadian engineering programs are expected to have reliably demonstrated the outcomes described in Figure 1. 
Figure 1.

High order graduate design outcomes

\begin{tabular}{|c|c|}
\hline $\begin{array}{c}\text { Design Process } \\
\text { Step } \\
\end{array}$ & Expected Outcome \\
\hline $\begin{array}{l}\text { Problem } \\
\text { Identification (and } \\
\text { Needs Analysis) }\end{array}$ & $\begin{array}{l}\text { - Identify and evaluate project } \\
\text { and stakeholder needs and } \\
\text { wants to (re)formulate a } \\
\text { complex problem or task into a } \\
\text { set of identified requirements } \\
\text { and evaluation criteria } \\
\text { satisfactory to all stakeholders }\end{array}$ \\
\hline $\begin{array}{l}\text { Information } \\
\text { Gathering }\end{array}$ & $\begin{array}{l}\text { - Seek out, access and } \\
\text { critically assess diverse } \\
\text { resources that are directly and } \\
\text { indirectly relevant to the } \\
\text { problem and its context }\end{array}$ \\
\hline Idea Generation & $\begin{array}{l}\text { - Generate original concepts } \\
\text { and adapt existing concepts to } \\
\text { offer diverse, viable solutions } \\
\text { that address the problem } \\
\text { definition }\end{array}$ \\
\hline Idea Selection & $\begin{array}{l}\text { - Use a convergent decision- } \\
\text { making and development } \\
\text { protocol to assess the } \\
\text { attributes and anticipated } \\
\text { outcomes of alternative } \\
\text { concepts relative to objectives } \\
\text { and constraints of the } \\
\text { identified problem to select a } \\
\text { preferred concept }\end{array}$ \\
\hline Detailed Design & $\begin{array}{l}\text { - Apply industry-standard } \\
\text { engineering judgment and } \\
\text { analyses to develop and } \\
\text { document a complete, } \\
\text { optimized design for } \\
\text { validation and implementation }\end{array}$ \\
\hline Validation & $\begin{array}{l}\text { - Use a formal methodology to } \\
\text { assess a proposed solution in } \\
\text { the full context of its } \\
\text { application to ensure that all } \\
\text { stakeholder needs and product } \\
\text { specifications are satisfied }\end{array}$ \\
\hline Implementation & $\begin{array}{l}\text { - Details the process by which } \\
\text { the project outcome will be } \\
\text { reproducible and manufactured } \\
\text { in a reliable, responsible and } \\
\text { efficient manner. }\end{array}$ \\
\hline
\end{tabular}

Once the "high-order" outcomes had been established, a sub-committee undertook the task of cross-referencing the design-based outcomes with the other eleven $\mathrm{CEAB}$ graduate attributes. In addition, suggestions for "lower-order" or course specific outcomes were included as illustrated in Figure 2. The previously outlined primary higher order or 'bundled' learning outcomes for each stage of the design process are supplemented here with sample 'unbundled' outcomes. The list of "unbundled" outcomes is by no means complete, but illustrates the general concept. In addition, examples of assignments and curriculum activities that enable students to demonstrate attainment of the outcomes are provided in some cases. The accompanying numerical notations indicate the CEAB Graduate Attributes that are embedded in the demonstration of each design process outcome.

Figure 2.

Example "unbundled outcomes" and embedded graduate attributes

\begin{tabular}{|c|c|}
\hline $\begin{array}{l}\text { Example course-specific/ lower order } \\
\text { outcomes }\end{array}$ & $\begin{array}{l}\text { Embedded } \\
\text { Attributes }\end{array}$ \\
\hline $\begin{array}{l}\text { Problem Identification (and Needs } \\
\text { Analysis) } \\
\text { Identifies and evaluates project and } \\
\text { stakeholder needs and wants to } \\
\text { (re)formulate a complex problem or task } \\
\text { into a set of identified requirements and } \\
\text { evaluation criteria satisfactory to all } \\
\text { stakeholders } \\
\text { Constructs problem statements } \\
\text { consistent with available information, } \\
\text { constraints and parameters of the } \\
\text { problem } \\
\text { Anticipates unstated customer/user } \\
\text { needs } \\
\text { Contributes as a member of a multi- } \\
\text { disciplinary team }\end{array}$ & $\begin{array}{l}3.1 .1 \\
3.1 .2 \\
3.1 .7 \\
3.1 .8\end{array}$ \\
\hline $\begin{array}{l}\text { Information Gathering } \\
\text { Seeks out, accesses and critically assesses } \\
\text { diverse resources that are directly and } \\
\text { indirectly relevant to the problem and its } \\
\text { context } \\
\text { Accurate use of technical literature } \\
\text { and other information sources } \\
\text { Distinguishes relevant information } \\
\text { from irrelevant } \\
\text { Uses a variety of methods (text, } \\
\text { graphs, plots, etc.) to explain, interpret } \\
\text { and assess information }\end{array}$ & $\begin{array}{l}3.1 .1 \\
3.1 .3\end{array}$ \\
\hline (continued on next page) & \\
\hline
\end{tabular}




\begin{tabular}{|c|c|}
\hline $\begin{array}{c}\text { Example course-specific/ lower order } \\
\text { outcomes (cont'd) }\end{array}$ & $\begin{array}{l}\text { Embedded } \\
\text { Attributes }\end{array}$ \\
\hline $\begin{array}{l}\text { Idea Generation } \\
\text { Generates original concepts and adapts } \\
\text { existing concepts to offer diverse, viable } \\
\text { solutions that address the problem } \\
\text { definition } \\
\text { Cites evidence to construct and } \\
\quad \text { support an argument }\end{array}$ & $\begin{array}{l}3.1 .1 \\
3.1 .6 \\
3.1 .9\end{array}$ \\
\hline $\begin{array}{l}\text { Idea Selection } \\
\text { Uses a convergent decision-making and } \\
\text { development protocol to assess the } \\
\text { attributes and anticipated outcomes of } \\
\text { alternative concepts relative to objectives } \\
\text { and constraints of the identified problem to } \\
\text { select a preferred concept } \\
\text { Applies probabilistic safety/risk/cost } \\
\text { analyses in decision-making } \\
\text { Analyzes components of a decision in } \\
\text { terms of ethical guidelines and } \\
\text { professional codes of ethics }\end{array}$ & $\begin{array}{l}3.1 .1 ; \\
3.1 .3 ; \\
3.1 .5 ; \\
3.1 .7 ; \\
3.1 .8 ; \\
3.1 .9 ; \\
3.1 .10 \\
3.1 .11\end{array}$ \\
\hline $\begin{array}{l}\text { Detailed Design } \\
\text { Applies industry-standard engineering } \\
\text { judgment and analyses to develop and } \\
\text { document a complete, optimized design for } \\
\text { validation and implementation } \\
\text { Combines scientific and engineering } \\
\text { principles to formulate models of } \\
\text { processes and systems } \\
\text { Estimates error and uncertainty in } \\
\text { measurement and instrumentation } \\
\text { Extrapolates mathematical principles } \\
\text { to analyze and solve engineering } \\
\text { problems } \\
\text { Takes steps to minimize risk to } \\
\text { clients, users and the environment } \\
\text { Incorporates standards and codes into } \\
\text { the decision-making process } \\
\text { Adapts the format and content of } \\
\text { reports of complex engineering } \\
\text { concepts for a variety of audiences }\end{array}$ & $\begin{array}{l}3.1 .1 \\
3.1 .2 \\
3.1 .3 \\
3.1 .5 \\
3.1 .7 \\
3.1 .8\end{array}$ \\
\hline $\begin{array}{l}\text { Validation } \\
\text { Uses a formal methodology to assess a } \\
\text { proposed solution in the full context of its } \\
\text { application to ensure that all stakeholder } \\
\text { needs and product specifications are } \\
\text { satisfied } \\
\text { Evaluates the validity and reliability } \\
\text { of models against specifications and } \\
\text { criteria }\end{array}$ & $\begin{array}{l}3.1 .8 \\
3.1 .9 \\
3.1 .10\end{array}$ \\
\hline $\begin{array}{l}\text { Implementation } \\
\text { Details the process by which the project } \\
\text { outcome will be reproducible and } \\
\text { manufactured in a reliable, responsible } \\
\text { and efficient manner. }\end{array}$ & $\begin{array}{l}3.1 .7 \\
3.1 .11\end{array}$ \\
\hline
\end{tabular}

\section{Implications}

The iterative and integrated nature of the design process has significant implications for the assessment of students' competence in the processes outlined. The committee acknowledges that every effort should be made to provide opportunities for students to demonstrate their ability to integrate, iterate, diverge and converge.

Professionalism relies on a disposition toward lifelong learning and institutions must take purposeful action in fostering such dispositions in its graduates. Successful students and professionals alike have the ability to identify and address gaps in their knowledge and skills by systematically identifying and accessing resources and opportunities for ongoing professional development.

Engineering, through design, is much more than the accumulation and demonstration of discrete competencies; it is the development and demonstration of integrated skills in the form of competence. The centrality of iteration and integration to the engineering design process means that the purposeful integration of graduate skills and attributes must become a focus for Canadian engineering programs.

At the outset of this study, there was no preconceived notion of the outcome. At no time prior to the formal working session was there any discussion that all eleven of the CEAB graduate attributes other than design, should be integrated within the design attribute. In fact, significant effort was made to find ways and words to describe the design attribute without using the other attributes as descriptors. It was only after this effort that the committee realized the obvious; engineering design is a process that spans the breadth of engineering, and as such, all of the other attributes are necessary elements of competence in design process, which, in essence, equates to competence in engineering.

It is also worthy to note that in the process of developing expected outcomes for design, the committee noted two further attributes that they considered to be of significant importance to graduate engineering competency, yet neither are explicitly stated in the CEAB ACP. They are:

- Information literacy/gathering - the ability to effectively source and interpret all relevant and necessary information required to develop an appropriate result

- Creativity - the ability to generate a wide variety of ideas/concepts/solutions that lead to effective and/or innovative results. 
Many engineering programs now include specific instruction in these areas as part of curriculum enhancement for innovation skills. While it might be suggested that these areas are implicit or expected within the twelve graduate attributes listed in the ACP, a case can be made for their inclusion as specific attributes, particularly with the growing drive for innovation to enhance economic growth.

\section{Summary}

The initial results from this study were presented at the National Canadian Deans of Applied Science and Engineering in November, 2010. The ad hoc NSERC Design Chairs committee was asked to be available for further consultation by the Dean's Education Committee as they continue their deliberations in responding to the CEAB ACP.

There is still much more work to be done in graduate attribute assessment and the information presented to the Dean's, and in this paper, is a work in progress. However, this study raises a very significant question with respect to the CEAB ACP: how can 3.1.4 "Design" be assessed as a stand-alone graduate attribute? It seems virtually impossible to isolate design without integrating all of the other attributes within the outcomes demanded by the design attribute. Even the description of engineering design provided in section 3.3.4.3 suggests this to be the case.

This then begs the two further questions. Can the 2008 CEAB ACP graduate attribute assessment process be effectively applied in the context in which it is written? Should graduate attributes be described within the context of engineering design process? It was not the intention of this study to raise such questions, yet the results demand they be considered. These are questions that the committee believe should be considered by engineering schools when developing their graduate attributes assessment protocols, and by the $\mathrm{CEAB}$ in future iterations of the ACP.

\section{References}

[1] T. Brzustowski, "Design Engineering and the Innovation Strategy", keynote presentation at the Canadian Design Engineering Network conference, 2004, Montreal, Canada

[2] Canadian Engineering Accreditation Board "Accreditation Criteria and Procedures", Engineers Canada, 2008

[3] G. Wiggins \& J. McTighe, "Understanding by Design", Alexandria, VA: Association for Supervision and Curriculum Development, 1999.
[4] S. Fostaty Young, "Teaching, Learning and Assessment in Higher Education: Using ICE to Improve Student Learning", Proceedings of the Improving Student Learning Symposium, London, UK, 2005 pp.105-115.

[5] S. Fostaty Young, "Theoretical frameworks and models of learning: tools for developing conceptions of teaching and learning", International Journal for Academic Development, 13(1), 41-49, 2008. 